\title{
ANTIMICROBIAL REAGENTS AS FUNCTIONAL FINISHING FOR TEXTILES INTENDED FOR BIOMEDICAL APPLICATIONS. I. SYNTHETIC ORGANIC COMPOUNDS
}

\author{
Madalina Zanoaga ${ }^{*}$, Fulga Tanasa \\ "Petru Poni" Institute of Macromolecular Chemistry, 41A, Grigore Ghica Voda Alley, Iasi, Romania \\ *email: zanoaga@icmpp.ro; phone: (+40 232) 2174 54; fax: (+40 232) 211299 \\ Paper dedicated to the $65^{\text {th }}$ anniversary of the \\ “Petru Poni” Institute of Macromolecular Chemistry of Romanian Academy, Iasi, Romania
}

\begin{abstract}
This article offers an overview of some contemporary antimicrobial agents used as functional finishing for textiles intended for biomedical applications. It reviews only synthetic agents, namely quaternary ammonium compounds, halogenated phenols, polybiguanides, $N$-halamines, and renewable peroxides. These agents can be divided into several groups according to their mechanism of antimicrobial activity, toxicity, durability and ecological acceptability. Examples of commercial antimicrobial products are presented herein, as well as the corresponding finishing methods.
\end{abstract}

Keywords: antimicrobial agents, structure, fibers, medical textiles.

\section{Introduction}

Textiles are ubiquitous and are used throughout the world for various purposes every day. In 2008, the world per capita fiber consumption was $10.4 \mathrm{~kg}[1,2]$. Nowadays, with the rapid changes in the social-economic structure of our society, textile materials (woven, nonwoven, knitted, and composites) have found various end-uses from apparels up to technical textiles [3]. The medical textiles sector, looked at in its broadest meaning, is undoubtedly one of the greatest success stories of recent years, in terms of the global technical textile industry. Medical textiles offer a variety of technical and functional properties, having applications in the field of medical and clinical care.

Common problem in hospitals and healthcare institutions is microbial contamination of surfaces, including textile fabrics, which can lead to infections and, consequently, to cross-infections. Irrespective of their applications, internal (surgical threads and various implants) or external (various extracorporeal devices such as catheters and hollow fibers for dialyzers, gauzes, bandages, nappies, tampons, and so on), medical textiles have to be comprised of basic bioactive properties, especially antimicrobial. Also, it is extremely important for protective clothing (surgical masks, caps, gowns, etc.) and hospital linen to meet the demands for antimicrobial protection.

Together, the abuse of antibiotics, new virus occurrence and prevalence of multi-resistant bacteria, such as meticillin-resistant Staphylococcus aureus (MRSA) and vancomycin-resistant Enterococcus (VRE), along with ageing of the population have generated the need for new and more efficient medical textiles.

Most synthetic textiles inherently resist against microorganisms (such as bacteria, fungi and mildew) attack, but are generally not inherently biocide. Further, the ability to inhibit growth of microorganisms does not reveal how fast or even whether the microorganism is destroyed. With natural fibers, however, there is a significant overlap of treatments which both protect the textile and attack the microorganisms $[4,5]$. Textile materials are susceptible anyway to microbial degradation because they provide an excellent environment for microorganisms to proliferate, because of their large surface area and ability to retain moisture. These microbes are found almost everywhere in the environment and can multiply quickly when basic requirements (such as moisture, nutrients and temperature) are met. Microbial load of textiles is maintained during storage and negatively affects the wearer during use, as well as the textile itself. These effects comprise product deterioration including discoloration, offensive odors, dermal infections, allergic responses and other diseases which are often associated. Therefore, it is highly desirable to minimize the growth of microbes on textiles during their use [4].

Accordingly, controlling the undesirable effects of microorganisms on textiles is becoming an important issue, especially within the medical textile industry. The detrimental effects can be controlled by durable antimicrobial finishing of textiles using broad-spectrum biocide or biostatic agents that prevent or inhibit the growth of microorganisms.

Estimations have shown that the production of antimicrobial textiles was in the magnitude of 30,000 tones in Western Europe and 100,000 tones worldwide in 2000 [5]. Furthermore, it was estimated that the production rate will increase, making it one of the fastest growing sectors of the textile market. Sportswear, socks, shoe linings and lingerie accounted for $85 \%$ of the total production. There is also a broader market for antimicrobial fibers, for instance, in medical textiles, outdoor textiles, air filters, automotive textiles, domestic home furnishings, etc. Consumers' attitude towards hygiene and active lifestyle has created a rapidly increasing market for antimicrobial textiles in order to protect the user from microorganism contamination. Another aspect of antimicrobial functional 
finishing of textiles is the addition of a therapeutic value to the material, intended for example, for wound healing [6-8].

As a consequence, the number of different technological approaches, antimicrobial agents and methods of binding them to the substrate, suitable for textiles, has increased significantly. A survey [1] listed the consumption of biocidal substances in Europe as 1546 metric tonnes for use in fibers, leather, rubber and polymeric materials and the demand for functional textiles with achieved antimicrobial activity is increasing. The development of new antimicrobials with enhanced activity is an ongoing topic of research and targets products ranging from synthetic organic compounds up to naturally based biocids [9-11]: quaternary ammonium compounds, dyes and regenerable $N$ halamines, polyhexamethylene biguanides, triclosan, peroxyacids, metals and metal oxides (silver, copper, titanium, cobalt, etc.), chitosan, essential oils, enzymes, natural pigments, etc.

This article reviews some of the most known antimicrobial agents and the corresponding finishing techniques used in order to obtain functional textiles for biomedical applications.

\section{Antimicrobial treatment of textiles: requirements and mode of action}

There is a growing volume of literature describing the survival and growth of microorganisms in textiles and their dissemination as a health risk. Textiles are not only carriers of microorganisms, but also good media for their proliferation. When the fabric is worn next to skin, infestation may cause cross infections by pathogens and odors development.

The antimicrobial functional finishes are applied to textiles in order to protect the wearer and the fabric itself [12], several objectives being achieved by this:

$>$ to prevent and control infestation, proliferation and cross infection;

$>$ to reduce odors and stains formation due perspiration and degradative processes;

$>$ to limit the deterioration of textiles, particularly fabrics made from natural fibers;

$>$ to control the spread of disease and danger of infection, inside and outside hospitals.

In order to obtain the greatest benefit, an ideal antimicrobial treatment should not only destroy undesirable microorganisms, but also satisfy a number of requirements concerning their effectiveness against a broad spectrum of bacterial and fungal species, low toxicity towards consumers, etc. [4,7,13]. Thus, first and foremost, the safety criterion must be considered: the product should not be excessively toxic to humans and the environment, and should not cause skin allergy and irritations of any kind. Second, the compatibility is defining the treatment quality: the product must not influence negatively on the textile properties and appearance, and must be compatible with common fibers and fabrics, as well as manufacture technologies. Last but not least, the durability of the product is decisive for its service life: it should be able to endure numerous laundering cycles, drying, and leaching. Researchers are now focusing on safe, durable, and environmentally friendly natural substitutes [14, 15].

According to their mechanism of antimicrobial activity, toxicity, durability and ecological acceptability, these agents can be divided into different groups [16]:

- biocides and biostats,

- leaching and bound antimicrobials,

- controlled-release and barrier-forming agents,

- agents of poor and good washing resistance.

These antimicrobial agents differ in their chemical structure, effectiveness, method of application, and influence on users and the environment, as well as production costs [5, 17-20].

In general, antimicrobials are similar to antibiotics in that they both inhibit microbes growth. But while the purpose of antibiotics is to cure disease, antimicrobials aim to prevent transmission of disease-causing microorganisms [21]. In the case of the antimicrobial textile finishes, their activity can be biocidal or biostatic. The biocides (bactericides and fungicides) include agents that destroy bacteria and fungi, whilst the biostats (bacteriostats and fungistats) inhibit the proliferation of microorganisms. The mode of action is directly related to and strongly dependent upon the concentration of the active substance in the textile finishing. The minimum inhibitory concentration (MIC) is required for biostatic activity, but for biocidal activity the minimum biocidal concentration (MBC) should be exceeded $[3,16]$.

A schematic illustration of different types of activity of an antimicrobial agent used for functional finishing of textiles is presented in Figure 1. As showed, antimicrobials may exert different actions onto pathogens depending on their inhibitory concentration (biostatic effect) or biocidal concentration (biocidal effect), yielding in a significant decrease in the number of CFU.

\section{Antimicrobial reagents used for textiles}

The growth rate of microbes can be astoundingly rapid. The bacteria population, for example, will double every 20 to 30 min under ideal condition $\left(36-40^{\circ} \mathrm{C}, \mathrm{pH} 5-9\right)$. At this rate, one single bacteria cell can increase to 1048576 cells in just 7 hours [22]. Therefore, antimicrobial finishes must be quick acting to be effective. 
There are several classes of antimicrobial agents used for antimicrobial functionalization of textiles [1]. The most prevalent antimicrobials for textile use include quaternary ammonium compounds (QAC), halogenated phenols (such as triclosan), metal-organic complexes (such as zinc pyrithione), polybiguanides (such as polyhexamethylene biguanides, PHMB), $N$-halamine compounds, metals and their corresponding oxides and salts, regenerable peroxides, etc. $[1,3,5,11,16]$, and some of them, namely synthetic organic compounds, are discussed below.

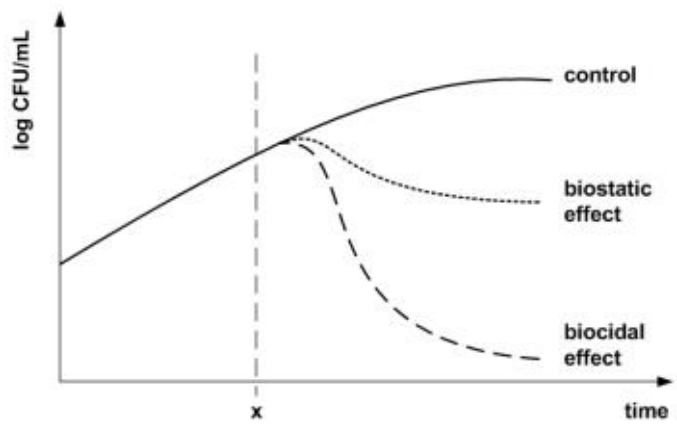

Figure 1. Effects of antibacterial agents on microbial growth rates (x - addition of an antimicrobial agent; CFU - colony forming unit) [3].

\section{Quaternary Ammonium Compounds (QACs)}

Quaternary ammonium compounds (QACs), particularly those containing chains of 12-18 carbon atoms, have been widely used as disinfectants. These compounds have a nitrogen atom bearing a positive charge which is responsible for the various detrimental effects on microorganisms. During bacterial inactivation, the quaternary ammonium groups remain intact and retain their antimicrobial activity as long as QACs are attached to textiles [5].

Cationic surface active agents (cationic surfactants), including particular quaternary ammonium salts (QASs), are important biocides known to be effective antiseptics [16]. As antimicrobial agents for textiles, monoammonium and "gemini" or "dimeric" ammonium surfactants (Figure 2) bearing alkyl, alkyl-aryl and perfluorinated hydrocarbon groups are used [23-25]. These are active against a broad spectrum of microorganisms such as Gram-positive and Gram-negative bacteria, fungi and certain types of viruses [26].

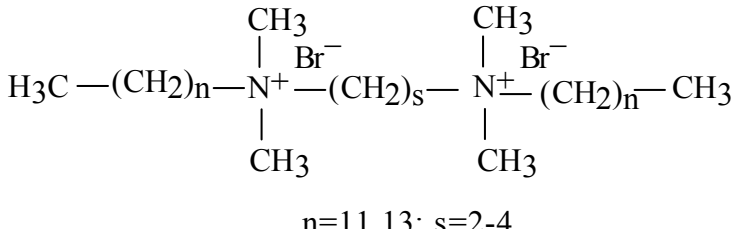

(A)<smiles>CCCCC(C)(C)[N+](C)(C)Br</smiles>

(B)

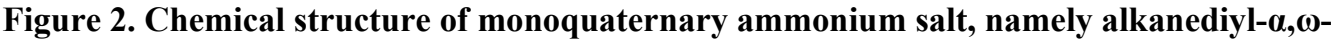
bis(dimethylalkylammonium bromide) (A) [24], and diquaternary ammonium salt, namely alkyltrimethylammonium bromide (B) [25].

The antimicrobial activity of QASs depends on a number of structural factors, as follows: the length of the alkyl chain, the presence of perfluorinated groups and the number of cationic ammonium groups in the molecule. The antimicrobial function arises from attractive interactions between the cationic ammonium group of the QAS and the negatively charged cell membrane of the microbe. These interactions consequently result in the formation of a surfactant-microbe complex. This, in turn, causes the interruption of all essential functions of the cell membrane and, thus, the interruption of cellular protein activity [27-29]. QASs also affect the bacterial DNA, causing a loss of multiplication ability [30].

If the QAS contains the cationic ammonium moiety bonded to a long hydrocarbon chain, two types of interactions between the agent and the microorganism can occur:

- a polar interaction with the nitrogen cation of the ammonium group, and

- a non-polar interaction with the long alkyl chain having hydrophobic character.

Penetration of the hydrophobic group into the microorganism occurs consequently, enabling the alkyl ammonium group to physically interrupt all the key functions of the cell.

Despite many positive properties, QASs have an inherent disadvantage, namely leaching from the textile due to its weak bonding to fiber or fabric. There are no reactive functional groups in the structure of the QAS as to allow 
its chemical bonding to the fibers. As consequence, leaching of the QAS from textile occurs, yielding in a fast decrease in concentration to values below the MIC. In addition, QASs have poor wash durability.

New and non-leaching, even permanently bonded, QAS biocidal groups have been designed especially for textile fibers. They are polymerizable QASs containing acrylate or methacrylate moieties, able to be incorporated in the fibers structure. Such QAS monomers have been named surfactant monomers or "surfmers". Under appropriate conditions, surfmers polymerize into a bulky polymer network having a polycationic structure, including side QAS groups chemically bonded to the main polyacrylate chain [31-33]. Some examples are given in Figure 3.

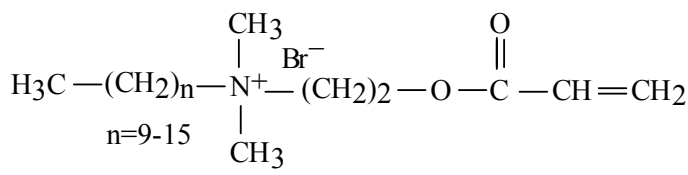<smiles></smiles>

(B)<smiles>C=CC[N+](I)(I)CCCCC(F)(F)F</smiles>

(C)

Figure 3. Chemical structures of some surfmers: A - alkyl(2-(acryloyloxy)ethyl)dimethyl ammonium bromide [31,32], B - benzyl(11-(acryloyloxy)undecyl)dimethyl ammonium bromide [32], C - N-(4,4,5,5,6,6,7,7,8,8,9,9,10, 10,11,11-heptadecafluoroundecyl)-N,N-diallylmethylammonium iodide [33].

QASs can act as a bio-barrier once they are chemically bonded to the textile surface and, therefore, kill microorganisms by contact. Furthermore, the formation of a polymer network on the fibers surface strongly increases the coupling durability and washing resistance of the biocide textile.

Different approaches were used to obtain antimicrobial textiles containing QASs, but the sol-gel technology has proven to be most appropriate because it enables the formation of a nanocomposite polymer network with an organic-inorganic hybrid structure [34-36]. Colloidal solutions (sols) have been prepared for this purpose, consisting of mixtures of tetraalkoxysilane $\left(\mathrm{Si}(\mathrm{OR})_{4}\right)$ and QASs with different structures [37] or organic-inorganic hybrids, including alkyl-trialkoxysilanes $\left(\mathrm{Rx}-\mathrm{Si}(\mathrm{OR})_{3}\right)$, with incorporated quaternary ammonium groups [30, 38-43], as presented in Figure 4.

Alkoxysilanes are sol-gel precursors with alkoxy groups that can hydrolyze in the presence of a catalyst to form silanol $(-\mathrm{SiOH})$ groups, which further condense among each other or with the hydroxyl $(-\mathrm{OH})$ groups of the textile fibers. The formation of covalent bonds between $-\mathrm{SiOH}$ groups of the sol-gel precursor and $-\mathrm{OH}$ moieties of the textile fibers yields in increased durability and washing resistance for the nanocomposite network on the finished antibacterial textiles. 
<smiles>CCCCC[N+](C)(C)CC[Si](C)(C)OC</smiles>

(A)

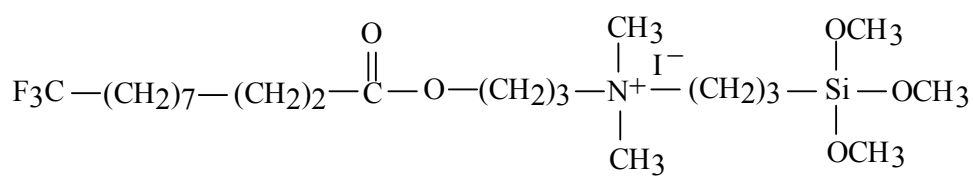

(B)

Figure 4. Chemical structures of alkyltrialkoxysilanes with incorporated quaternary ammonium groups: alkyl-dimethyl-(3(trimethoxysilyl)-propyl) ammonium bromide (A) $[38,42]$ and perfluorooctylated quaternary ammonium silane coupling agent (B) [41].

Another group of ammonium functional finishing for biocide textiles is quaternary ammonium functionalized polyhedral oligomeric silsesquioxanes (Q-POSS) which are used as sol-gel precursors with antimicrobial properties [44-49]. These quaternary ammonium compounds have a cage-like structure of $\left(\mathrm{R}_{\mathrm{x}}-\mathrm{SiO} \mathrm{O}_{1.5}\right)_{\mathrm{n}}$ (where $n=6,8,10,12, \ldots)$ and $R_{x}$ is a QAS group [44,45]. Octasilsesquioxanes $(n=8)$ which have a cubic form with QAS groups bound to silicon atoms are the most often used POSS precursors. Accordingly, up to eight QAS groups can be incorporated into each molecule (see Figure 5), thus enhancing their antimicrobial activity. Because Q-POSSs possess a polysiloxane core compatible with the siloxane matrix, they can be used as additives to polysiloxane coatings in combination with polydimethylsiloxane.

A commercial antimicrobial textile product using QAC as the active agent is the BIOGUARD® produced by AEGIS Environments. The active substance, 3-trimethoxy-silyl-propyl-dimethyl-octadecyl ammonium chloride (AEM 5700, formerly known as the Dow Corning 5700 Antimicrobial Agent; see Figure 6), has a MIC of 10-100 $\mathrm{mg} / \mathrm{l}$ against Gram-positive and Gram-negative bacteria [46].

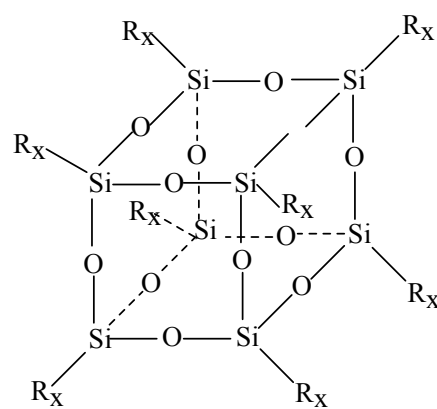<smiles></smiles>

Figure 5. Schematic presentation of an idealized structure of totally quaternized quaternary ammonium functionalized polyhedral oligomeric silsesquioxanes [44].

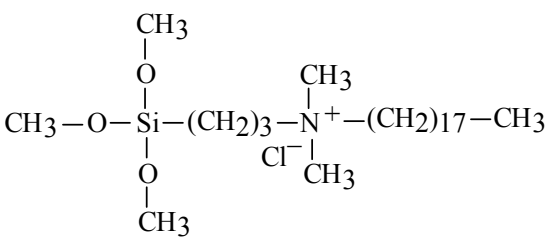

Figure 6. Structure of AEM 5700, namely3-(trihydroxysilyl) propyldimethyl-octadecyl ammonium chloride [44].

AEM 5700 is prepared as aqueous solution and applied by padding, spraying and foam finishing. Upon drying, the non-volatile silane forms covalent bonds with the textile, resulting in excellent durability [47]. So far, this reagent has been commercially used on cotton, polyester and nylon fabrics.

Other important antimicrobials for textile applications are substituted polycationic polysiloxanes with pendant QAS or imidazolium salt groups, which demonstrated biostatic effect. They are mostly copolymers consisting of polydimethylsiloxane, polymethylhydro-siloxane and QAS- or imidazolium-modified polysiloxanes in different molar ratios. Their structures are presented in Figure 7. 


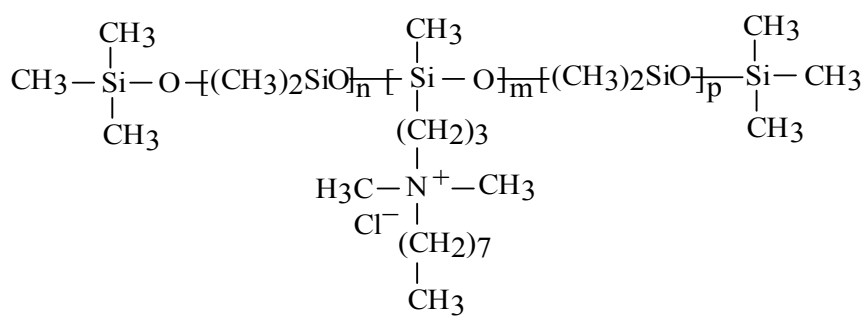

(A)

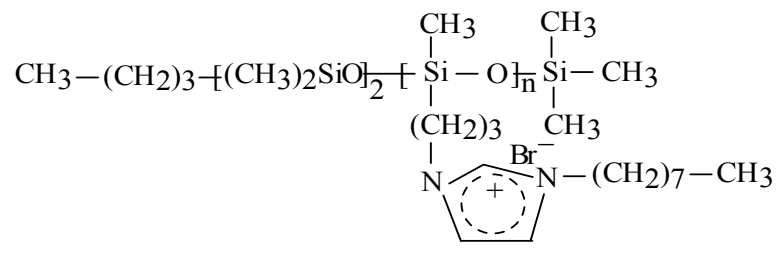

(B)

Figure 7. Substituted polycationic polysiloxane with pendant QAS (A) [45] and imidazolium salt (B) [49] groups.

QACs with relevant antimicrobial activity are mono- and diazoic dyes, as well as anthraquinone-based dyes, containing one or even two QAS moieties with different structures (Figure 8).<smiles>CCCC[N+](C)(C)CC(O)CNc1cccc2c1C(=O)c1ccccc1C2=O</smiles><smiles>C[14CH2]C[N+](C)(Br)CCOc1ccc(N=Nc2ccc(N(C)C)cc2)cc1</smiles>

(B)<smiles>C[AlH]C[N+](C)(C)[Ge]COc1nc(Cl)nc(Nc2cccc3c2C(=O)c2ccccc2C3=O)n1</smiles>

(C)

Figure 8. Antimicrobial cationic anthraquinone-based dye (A) [50,51], monoazoic dye (B) [52]

and anthraquinone-based reactive dye $(C)$ [53] containing QAS.

These novel cationic dyes have biostatic activity due to the chemically bonded QAS groups [50-55]. Owing to the QAS content, the di-substituted dyes have higher antimicrobial activity than mono-substituted ones [50]. The other structural factor affecting QACs activity is the chain length: the longer the chain of the QAS groups in the dye structure, the more intense the antimicrobial activity [50,54]. 
Cationic anthraquinone-based dyes can be effectively introduced into acrylic fibers in order to simultaneously achieve coloration and antimicrobial function. However, the wash durability of the treated acrylic fabric is low [51]. To improve the wash durability of antimicrobial dyes on cotton fibers, an anthraquinone cationic reactive dye (Figure 8C) has been synthesized by chemical binding a QAS group to the reactive $s$-triazine group of the dye by a nucleophilic substitution [53]. This reactive cationic dye has been applied to cotton fibers with high exhaustion and fixation rates, without the addition of any salt as electrolyte. Although the dyed cotton exhibits good color retention after washing, antimicrobial function decreased after repetitive washing, due to the deactivation of quaternary ammonium groups by their reaction with negatively charged anionic units from detergent.

The biocide action depends on both the size of the molecule and the functional group density. Larger molecules tend to have lower permeation through cell membranes and, thus, appear less biocidal. Dendrimers have attracted attention as possible antimicrobial agents due to their compact structure and availability of many end groups. Dendritic biocides containing quaternary ammonium groups are interesting because their functional group density increases with their size, suggesting that an optimal size and biocide activity can be reached [56-58]. The structure of a 4-generation poly(propyleneimine) dendrimer with 32 surface primary amine groups is shown in Figure 9.

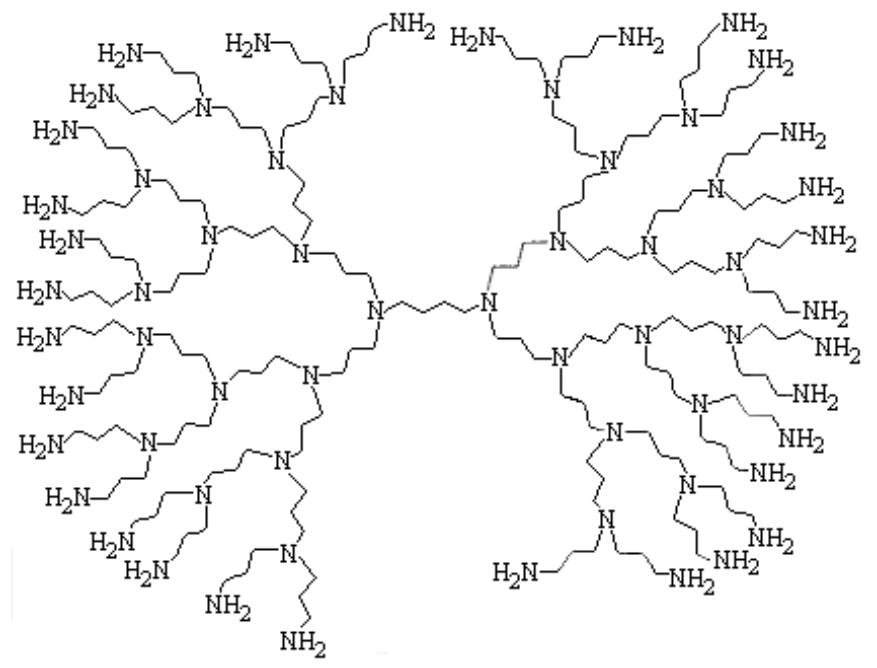

Figure 9. A 4-generation poly(propyleneimine) dendrimer with 32 surface primary amine groups (according to [56]).

Recently, a series of highly effective quaternary ammonium functionalized poly(propyleneimine) dendrimers was synthesized [56]. Their biocidal properties depend on the size of the dendrimers used, length of the hydrophobic chain in the quaternary group, and counter anion. It was observed that these novel biocides with bromide anions are more efficient than those with chloride anions.

The attachment of QACs to textile substrates is believed to take place predominantly by the ionic interaction between cationic groups in QACs and anionic ones at fibers surface [59,60].

Thus, for polyester fibers such as Acrilan $^{\circledR}$ (from Acrilan) and Orlon ${ }^{\circledR}$ (from DuPont) which contain carboxylic or sulfonate groups, QACs can be directly bridged under specific conditions (near boiling temperature) [61-63].

Other synthetic fibers, such as nylon, contain fewer reactive sites and are quite resistant to chemical modification procedures, including antimicrobial finishing. QACs have been substantively bound to nylon fibers using acid dyes as bridge and the modified fibers achieved biocidal properties, but displayed some strength issues. It is considered that dye molecules may act as bridges to bind QACs to the fibers surface [64]. The fabrics were first dyed with acid dyes before QACs were applied under alkaline conditions. The ionic interaction between the dye molecules and the QAC was sufficiently strong to provide a semi-durable antimicrobial finishing [59, 60, 64].

Similarly, the glutamyl and aspartyl residues in wool provide carboxylic groups able to bind QACs. Particularly, cetylpyridinium chloride can render it antimicrobial activity to wool upon corresponding treatment, with durability up to 10 launderings $[65,66]$.

Nevertheless, attempts have been made to covalently attach QAC onto wool. A new QAC, $N$-dodecyl-aminobetaine-2-mercaptoethylamine hydrochloride (DABM) was synthesized $[67,68]$ and it can react with wool by means of its thiol group, either with cysteine-S-sulphonate residues (Bunte salts) of sodium bisulphite pretreated wool or with the disulfide bond of cystine wool, forming an asymmetrical disulfide bond. Such covalent attachment of the quaternary ammonium surfactant provides antimicrobial activity. 
Cotton fabrics have been treated in the presence of a 4-aminobenzenesulfonic acid-chlorotriazine adduct which increased the number of anionic sites on the fabric surface and facilitated the QACs binding [69]. In general, these studies considered the influence of the solution $\mathrm{pH}$, the QAC concentration, temperature, and exhaustion time.

Some antimicrobial products for textile application are currently commercially available under specific trade names. Thus, Dow-Corning produced a series of quaternary amines which could be fixed to a surface via silane coupling reaction [70-72]. Aegis Environments (Midland, Michigan), a spin-off company, has developed the technology under the trade name Microprobe Shield ${ }^{\circledR}$. The product is used in a wide cross-section of the textile industry - nonwovens, wipes, medical wear, socks, athletic apparel, uniforms, floor mats, ceiling tiles etc. Other companies are also involved in research and development of such antimicrobian agents for functional finishing of textiles [73].

\section{Halogenated phenols}

Halogenated phenols are a group of organic reagents known for their antimicrobial activity and, therefore, widely used as antiseptics and disinfectants, fungicides and pesticides. There are a few very famous members of this class, such as triclosan (2,4,4-trichloro-2-hydroxydiphenylether), diclosan (5-chloro-2-(4-chlorophenoxy)phenol), chloroxylenol (4-chloro-3,5-dimethylphenol, currently used in the Dettol formulation, along with other components), trichlorophenyl-methyl-iodosalicyl (also known as TCP and it combines antiseptic effects of both halogenated phenols and salicylic acid derivatives), as well as Tinosan ${ }^{\circledR}$ which encompasses active biocidal agents such as diclosan (see Figure 10).<smiles>Oc1cc(Cl)ccc1Oc1ccc(Cl)cc1Cl</smiles>

(A)<smiles>Oc1cc(Cl)ccc1Oc1ccc(Cl)cc1</smiles>

(B)<smiles>Cc1cc(O)cc(Cl)c1Cl</smiles>

(C)<smiles>Oc1c(Br)cc(Br)cc1Br</smiles>

(D)

Figure 10. Structure of the most known halogenated phenols:

\section{A - triclosan (2,4,4-trichloro-2-hydroxydiphenylether) [3] (according to PubChem Compound, CID 5564), B - diclosan (5-chloro-2-(4-chlorophenoxy)phenol) (according to PubChem Compound, CID 18807), C - chloroxylenol (4-chloro-3,5-dimethylphenol) (according to PubChem Compound, CID 2723), D - 2,4,6-tribromophenol (according to PubChem Compound, CID 1483).}

Recent investigations evidenced the efficiency of natural compounds with similar structure, such as 2,4,6tribromophenol found in significant amounts in different species of Antarctic sponges [74].

Attention has been drawn to these compounds due not only to their biocide activity, but also to their structural similarity with highly toxic contaminants, such as dioxins and halogenated phenolic compounds (HPCs) (including hydroxylated polychlorobiphenyls (OH-PCBs) and hydroxylated polybromodiphenyl-ethers (OH-PBDEs) which are persistent organic pollutants [75]). The possibility of their conversion into these hazardous compounds may represent a potential health risk to human (e.g., dermal irritation) and wildlife, as well.

Among halogenated phenols, triclosan is the most widely used biocide; it is present in many contemporary consumer and personal health-care products, detergents and household objects, including textiles and plastics. At bactericidal concentration, triclosan is very effective against a broad range of microorganisms, including antibioticresistant bacteria, but it also has some antifungal and antiviral properties [16,21].

The mechanism of triclosan antimicrobial effect is based mainly on the inhibition of fatty acid biosynthesis through blocking lipid biosynthesis, as well as on the interaction with aminoacid residues of the enzyme-active site within the membrane [76]. As the widespread use of triclosan could represent a potential risk in terms of the development of resistant microorganisms [16], strong binding to textiles surface and subsequent controlled release is required.

As a textile finish, it is mostly used for the protection of industrial and transport filters, the production of antimicrobial shoe-socks, socks, towels, cleaning wipes and for household textiles [3].

A cotton knitted fabric treated with $6 \%$ triclosan solution by the conventional exhaust process has shown an effective reduction of bacteria Staphylococcus aureus and Escherichia coli. After 50 laundering cycles, antimicrobial activity decreased, but the reduction was still over $70 \%$. The activity in acidic, basic and synthetic urine conditions was also reduced [76].

Unlike most other cationic biocides used on textiles, triclosan is not ionized in solution. Triclosan has, therefore, been applied to cellulose fibers in combination with polycarboxylic acids as crosslinking agents [77]. The application of polycarboxylic acid to fibers previously finished with triclosan enhances the washing durability of the antimicrobial coating. 
To achieve a more durable finishing, novel host-guest inclusion complexes have been prepared using triclosan and cationic $\beta$-cyclodextrins (torus-shaped cyclic oligosaccharides containing six to eight glucose units linked by $\alpha-1,4$ bonds), based on the ability of small molecules to penetrate into the hydrophobic cavity of $\beta$ cyclodextrins (Figure 11).

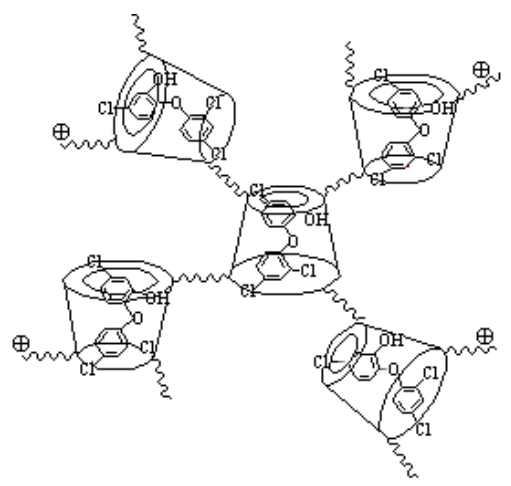

Figure 11. Schematic illustration of host-guest inclusion complexes of triclosan and $\beta$-cyclodextrin (according to [78]).

Water solubility, stability and antimicrobial activity have been determined for the host-guest complexes $[78,79]$. Owing to strong electrostatic attraction, the complexes are adsorbed to the surface of cellulose fibers almost completely.

In another approach, triclosan has been encapsulated in microspheres made of biodegradable polylactide and immobilized onto nonwoven viscose textiles [80].

Cotton and cotton blends can be submitted to functional finishing with triclosan mixed with a polyurethane resin and a plasticizer [81] with good results.

Being a relatively small molecule, triclosan can also act like a disperse dye and can be used by exhaustion prior to dyeing, together with dyeing or after dyeing of polyester and nylon fibers at $5 \%$. During the fabric use, the agent migrates to the treated textiles surface at a slow, yet sustained, rate as to provide antimicrobial efficacy [82].

Triclosan can also be directly incorporated into synthetic polymers through melt-mixing or suspension polymerization $[83,84]$. A number of companies manufacture and market triclosan-based fibers, yarns or fabrics. For instance, the nylon and polyester products Tinosan AM $100^{\circledR}$ and CEL $^{\circledR}$ (Ciba Speciality Chemicals), the Silfresh ${ }^{\circledR}$ cellulose acetate yarn (Novaceta) and Microban ${ }^{\circledR}$ textile products (Microban International), all contain triclosan as the active antimicrobial agent which is applied during the finishing stage or is incorporated into the fiber during extrusion $[85,86]$. Fibers using triclosan are available from Synthetic Industries (olefin), Sterling Fibers (acrylic), and Cydsa (acrylic), as well as from several other suppliers of acetate, olefin, and acrylic fibers. Finishes for fabrics including polyester and cellulose are available [87,88].

Literature is abundant in data concerning the bacterial resistance towards triclosan. Despite of its antimicrobial activity, triclosan breaks down into toxic compounds when exposed to sunlight in the environment (in example, 2,8-dichlorodibenzo- $p$-dioxin which is chemically related to other toxic polychlorinated dioxins). The chemical structure of triclosan is quite similar to that of diethylstilbestrol (DES), a non-steroidal estrogen, and it is raising concerns about its potential as an endocrine disruptor. Recent studies showed that triclosan can significantly affect the thyroid gland activity [89], at exposure levels equivalent to those currently found in the environment and human tissues, and exhibit weak androgenic effects [90]; there is no evidence that triclosan is a carcinogen or teratogen [91].

Due to the health and environmental issues, the scientific community is concerned about the long term effects [92] and analyses the opportunity to limit the triclosan use in textiles and some other products.

\section{Polybiguanides}

Polybiguanides are polymeric polycationic amines that include cationic biguanide repeating units separated by hydrocarbon chain linkers of identical or dissimilar length [16] (Figure 12). One of the most important antimicrobial agents among them is PHMB, poly(hexamethylenebiguanide) which has an average of 11 biguanide units (Figure 13) [93,94]. 


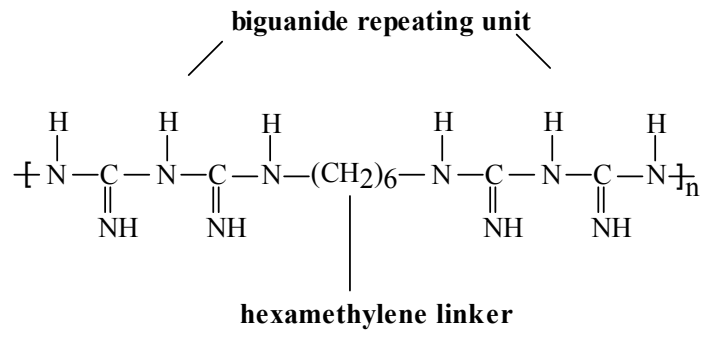

Figure 12. Structure of biguanide units linked by a hexamethylene spacer (according to [16]).

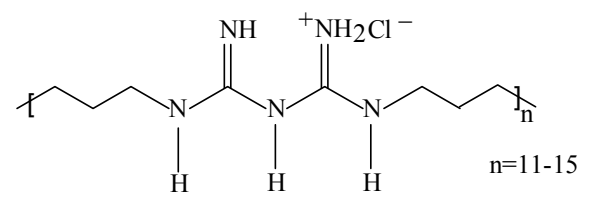

Figure 13. Poly(hexamethylenebiguanide) hydrochloride structure [94].

PHMB exhibits much greater antimicrobial activity than the corresponding monomeric or dimeric biguanides, chemical stability, and low toxicity, all at a reasonable cost. Its maximal biocidal efficiency is due to both cationic structure $\left(\mathrm{H}_{2} \mathrm{~N}^{+}\right)$and flexible spacer, a hexamethylene group, between biguanide repeating units. PHMB is, therefore, widely used in medicine as an antiseptic agent for textiles, especially for preventing wound infection by antibiotic-resistant bacteria $[95,96]$. It also has several other interesting properties that make this material suitable as a building block for supramolecular chemistry and "smart" materials [97].

In a comparative investigation on the antiseptic efficacy, some of the most known and used antimicrobial agents were studied [98]:

- triclosan - a halogenated phenol (see section 3.2.),

- octenidine - a bis(dihydropyridinyl)-decane derivative, similar in its action to the quaternary ammonium compounds,

- PHMB,

- PVP-Iodine - a stable chemical complex of polyvinylpyrrolidone (PVP) and elemental iodine, and

- chlorhexidine digluconate - a cationic polybisbiguanide used primarily as its salts, namely dihydrochloride, diacetate and digluconate.

It was concluded that PHMB was the most effective and recommended when prolonged use is needed and/or when prolonged contact is feasible.

The biocide activity of PHMB was studied and it was highlighted that it acts through multiple mechanisms. The attachment of PHMB induces shifts in the physical properties of membranes. It disorganizes the cytoplasmatic membrane of microbes, leading to increased membrane permeability. The study reveals phase transitions (solid/liquid) in membranes into more fluid and rigid domains. The outer surface of bacteria is universally negatively charged and usually stabilized by divalent magnesium and calcium cations. PHMB replaces these ions and, therefore, has a natural affinity for the membranes of both Gram-positive and Gram-negative bacteria, as well as other microorganisms [99]. It was also demonstrated that PHMB activity increases on a weight basis with increasing levels of polymerization. To date, bacterial resistance to PHMB has rarely been observed, although resistance to the bisbiguanide chlorhexidine is well known $[5,100]$.

Wound dressings are one of the most known textile applications of PHMB, due to its low toxicity $(\mathrm{MIC}=0.5-10 \mathrm{ppm})$. The literature indicates that PHMB can bind to the anionic carboxylic groups of cellulose (Figure 14), which are formed through oxidation of glucose rings during pre-treatment processes, such as bleaching and mercerizing [16].

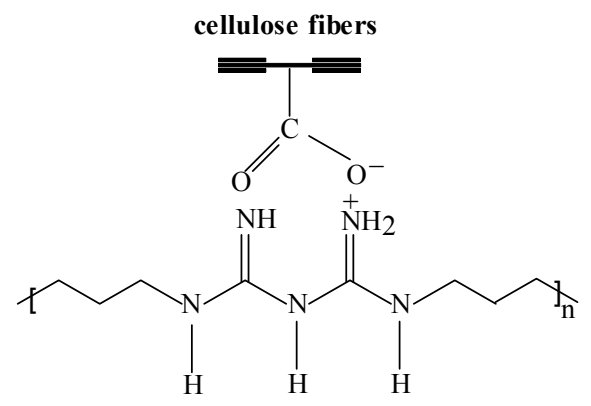

Figure 14. PHMB binding to the carboxylic group of cellulose [16].

At lower concentrations, electrostatic interactions between PHMB and carboxylic groups in the cellulose dominate; however, hydrogen bonding of PHMB with cellulose resulting in multilayer adsorption becomes increasingly dominant as the concentration of PHMB increases. The adsorption of PHMB increases if cellulose fibers 
are previously dyed with anionic reactive dyes [94], which provide sulfonic acid sites able to link PHMB. However, strong PHMG-dye interactions cause a reduction in its antimicrobial activity, which is undesirable.

Another finishing approach for PHMB-treated cotton fibers involves an after-treatment with a strong organic acid used to increase durability, as well as to overcome fabric yellowing. PHMB can also be directly exhausted onto cotton at room temperature and neutral $\mathrm{pH}$ or applied in a pad-dry-cure process. PHMB needs to be applied in an amount of $2-4 \%$ for durable finishing and $0.25-1 \%$ for disposable items. The PHMB treatment was extended to synthetic fibers using a self cross-linkable resin and a catalyst [5].

Special grades of PHMB, namely Vantocil ${ }^{\circledR}$ and Reputex ${ }^{\circledR}$, have been developed. The primary performance benefits of Vantocil ${ }^{\circledR}$ include: fast-acting and broad spectrum antimicrobial activity; no cross-resistance with therapeutic antibiotics; high level of retained biocidal activity in both soft and hard water conditions, and in the presence of organic load (bovine serum albumin, yeast extract, milk and sucrose); stable and effective performance over a $\mathrm{pH}$ range of 1-11; low surface activity; provide very low foaming [101]. Reputex ${ }^{\circledR}$ has a higher molecular weight than Vantocil ${ }^{\circledR}$, containing an average of 16 biguanide units in the polymer. This longer polymer length not only results in higher biocide activity, but also provides more cationic sites per molecule for a possibly stronger binding to the textile surface. Reputex ${ }^{\circledR}$ was initially applied to cotton or its blends, using exhaust or pad-dry-cure processes, and more recently to polyester and nylon [102], under the trade name Purista ${ }^{\circledR}$.

\section{N-Halamines}

$\mathrm{N}$-halamines are heterocyclic organic compounds containing one or more nitrogen-halogen $(\mathrm{N}-\mathrm{X})$ covalent bonds that are normally formed by the halogenation of imide, amide, or amine groups. Other $N$-halamines containing different reactive groups, such as sterically hindered hydantoins, imidazolidones and oxazolidinones, proved to be effective for textile applications [73]. Their antimicrobial properties, proven for a broad spectrum of bacteria, fungi and viruses, are based on the release of chlorine by its electrophilic substitution with $\mathrm{H}$ in the $\mathrm{N}-\mathrm{Cl}$ bond. This reaction can be carried out in the presence of water and results in the presence of free chlorine cations able to bind to the acceptor regions on microorganism and, subsequently, hinder their enzymatic and metabolic processes, leading to microorganism destruction. During the interaction with microbial membrane, the $N$-halamine bond is reversibly converted into $\mathrm{N}-\mathrm{H}$ bond (which has no biocide activity) and has to be exposed to hypochlorite solution (e.g., during bleaching or laundering) for its regeneration (as presented in Figure 15) and antimicrobial activity recovery $[103,104]$.

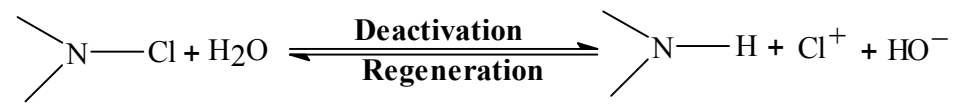

Figure 15. Reaction mechanism of $N$-halamine compounds $[3,5]$.

$N$-halamines can be applied to various textile surfaces including cellulose [104], polyamide [105] and polyester [106] fibers. To increase their effectiveness and the durability of the antimicrobial finish [104], research has been oriented toward synthesis of $N$-halamide monomers with an incorporated vinyl reactive group (Figure 16) that can polymerize on cellulose fibers under appropriate conditions to form a coating with excellent durability after washing [16].<smiles>C=Cc1ccc(CN2C(=O)N(C)C2(C)C)cc1</smiles>

(A)<smiles>C=C(C)C(=O)OC1CC(C)(C)N(Cl)C(C)(C)C1</smiles>

(B)

Figure 16. Chemical structure of 3-(4'-vinylbenzyl)-5,5-dimethylhydantoin (A) [106] and $N$-chloro-2,2,6,6-tetramethyl-4-piperidinyl methacrylate (B) [16]. 
Cellulose treated with methylol-5,5-dimethylhydantoin in combination with hypochlorite forms chloramines on the fiber surface [3]. Nevertheless, the fabrics yellowing and their strength loss occur when high concentrations of chloramines are used, affecting textiles not only from practical point of view (they become brittle), but also esthetic due to the unpleasant chlorine odor.

Moreover, covalent binding of $N$-halamines to the cellulose surface is ensured by two different methods:

- the preparation of $N$-halamine precursors containing two hydroxyl groups, which can be chemically bonded to hydroxyl groups from cellulose fibers surface in the presence of 1,2,3,4-butantetracarboxylic acid (BTCA) as cross linking agent [107], or

- the synthesis of $N$-halamine siloxane monomer precursors, which allow the silanol groups to react with the cellulose hydroxyl groups to form a nanocomposite coating, as presented in Figure 17: A is 4-[3-triethoxysilylpropoxyl]-2,2,6,6-tetramethylpiperidine [108], B is 5,5-dimethyl-3-(3'-triethoxysilyl-propyl)-hydantoin [105], C is 3-(3-triethoxysilyl-propyl)-7,7,9,9-tetramethyl-1,3,8-triazaspiro[4.5]decane-2,4-dione [105].<smiles>CCO[Si](CCOC1CC(C)NC1(C)C)(OCC)OCC</smiles>

(A)<smiles>CCO[Si]1(OCC)CCN(C(=O)NC(=O)C(C)(C)C)CCO1</smiles>

(B)<smiles>CCO[Si](CC)(OCC)OCC</smiles>

(C)

Figure 17. Chemical structure of different $N$-halamine siloxane precursors $[105,108]$.

In addition, the study showed that copolymers incorporating $N$-halamine siloxane and QAS siloxane by synthesis, namely poly[3-(5,5-dimethylhydantoinylpropyl)siloxane-co-3-dimethyldodecylammoniumpropyl-siloxane chloride] (Figure 18), displayed enhanced antimicrobial behavior due to the synergistic action of these agents.<smiles>CC[N+](C)(C)C[Si](O)(O[Al])O[Si](C)(O)CN1C(=O)NC(C)(C)C1=O</smiles>

Figure 18. Chemical structure of hydantoinyl/quat siloxane copolymer [104].

Different heterocyclic $N$-halamine compounds have been covalently attached to various types of fibers, ranging from nylon [109] and polyester [110], to cotton [5] and keratinous fibers [111]. Another method to covalently attach these biocide compounds is to graft them onto cellulosic fabrics [3,5,16], as well as synthetic fabrics, mostly made of high performance polymer fibers such as: polyethylene terephthalate (PET), nylon-66 (PA), polypropylene (PP), acrylic fibers (Orlon), polyester/polyamide (PET/PA=70/30) blend microfibers, polyethylene (PE), Nomex $(m-$ aramid fibers), Kermel (polyamid-imide fibers), poly-[2,2'-( $m$-phenylen)-5,5'-bisbenzimidazole]/Kevlar (PBI/paramid) blend fibers $[112,113]$. A schematic illustration of the covalent bonding reaction of $N$-halamine compounds on polyamide and polyester fibers is presented in Figure 19. 


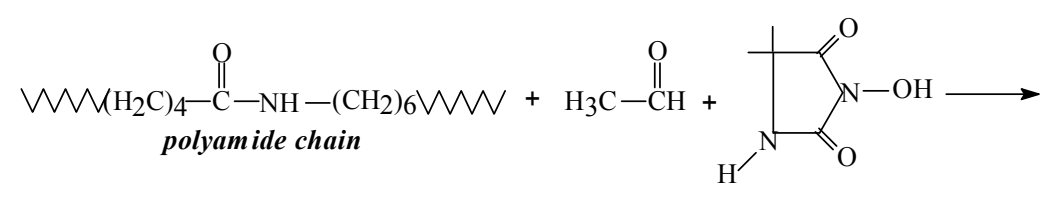

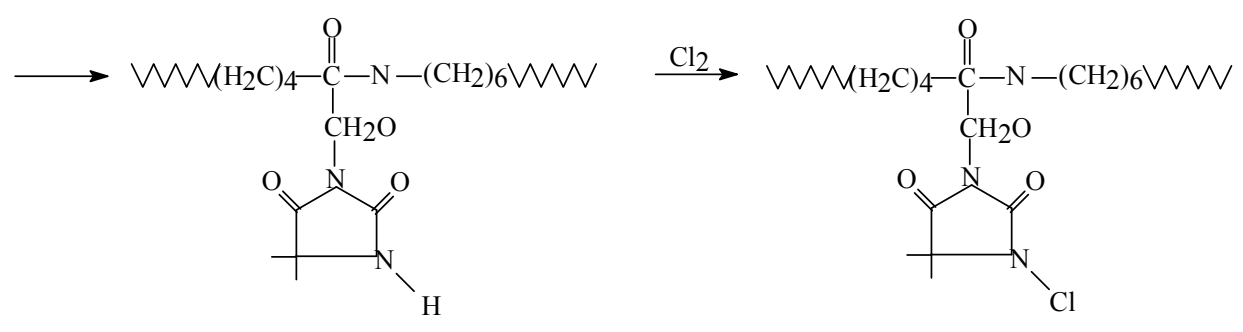<smiles>CC(C)CNC(=O)N(CO)C(=O)C(C)(C)C</smiles>

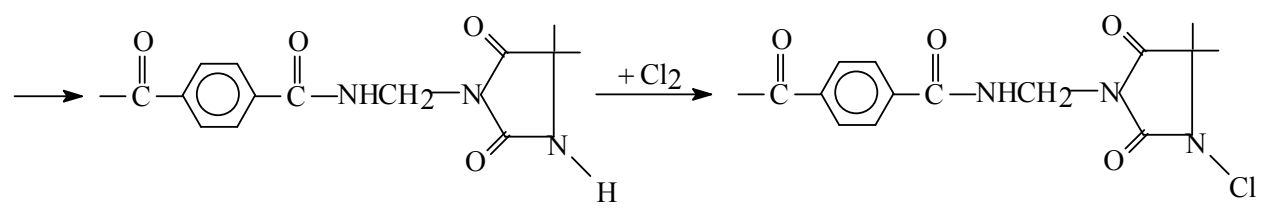

Figure 19. Reaction of $N$-halamine compounds with polyamide and polyester, respectively [73].

Antimicrobial nanofibrous nylon 6 membranes were fabricated with $N$-halamine additives through electrospinning. $N$-halamines generally contain one or more imide, amide or amine halamine bonds [114]. The antimicrobial activity of $N$-halamines increases in the following sequence: imide $>$ amide $>$ amine halamines, which is in a reverse order of their stability. Three structurally different $N$-halamines were introduced into the electrospinning dope of nylon 6 as antimicrobial additives:

- chlorinated 5,5-dimethylhydantoin (CDMH), containing an imide and amide halamine group;

- chlorinated 2,2,5,5-tetramethyl- imidozalidin-4-one (CTMIO), with an amide and amine halamine group and

- chlorinated 3-dodecyl-5,5-dimethylhydantoin (CDDMH), which has an amide halamine group and a long alkyl chain.

At same active chlorine content, CDMH-nylon 6 fibers proved to be the faster in antimicrobial action, while CDDMH-nylon 6 ones acted much slower, due to the slower reaction rate of chloro-amide group and the inhibition caused by the attached long alkyl chain. The antimicrobial action of electrospun CTMIO-nylon 6 membranes was of similar rate as that of CDDMH-nylon 6 ones.

In another comparative study, cellulose and $m$-aramid fibers, as well as composite cellulose $/ m$-aramid fibers, were treated with an $N$-halamine as ionic liquid, namely 1-butyl-3-methyl-imidazolium chloride, in order to achieve biocide activity [115]. Stable and rechargeable composite cellulose/m-aramid fibers were prepared by dry-jet wet spinning of a mixed polymer solution. These fibers showed a much higher chlorination level than the pure $m$-aramid fiber and retained their antimicrobial properties for over 50 standard washing cycles.

As general procedure, the antimicrobial activity of functional textiles can be readily recovered by washing them in chlorine aqueous solution. The residual adsorbed (unbounded covalently) chlorine produces an unpleasant odor and discolors fabrics. A reduction step (i.e., with sodium sulfite) [116] may be used to remove the chlorine excess from the fabric surface, which is a convenient approach to overcome this problem.

\section{Regenerable peroxides}

Alternate methods for textiles functional finishing employ renewable antimicrobial agents. One example may be $N$-halamines. Another approach is using peroxydic moieties, such as peroxide and peroxyacids, which have been widely used as disinfectants in the food and beverage industries, as well as bleaching agents for textiles and paper [117]. A classic example is the peroxyacetic acid which is well known as a powerful disinfectant used in hospitals [118]. 
Peroxyacids are converted to carboxylic acid during their biocide action, but can be easily regenerated through the reaction with an oxidant (e.g., hydrogen peroxide) [119], as showed in Figure 20.<smiles>[R]C(=O)O[14CH2][14CH2][14CH2][14C](=O)O</smiles>

Figure 20. Regeneration reaction of peroxides [119].

As for their mode of action, peroxydic compounds attack the microbe cell membrane, get into the cytoplasm and affect the microorganism enzymes [120].

The formation of peroxyacids on cellulose fibers can be carried out in two steps: (1) grafting/crosslinking polycarboxylic acids (PCAs) onto cellulose, and (2) oxidation of unreacted free acid moieties of cellulose-linked PCAs up to the corresponding peroxyacid units [117]. This reaction (2) may be performed either in an oxygen bleach bath [118] or with strong oxidants, such as sodium perborate [121]. The feasibility of grafting BTCA (butane tetracarboxylic acid) or citric acid onto cotton fabrics by a pad-dry-cure process, similar to cotton durable press, was also investigated [119, 121].

Such functional finishing can be applied not only to cotton (cellulose) fibers, but to polyester fabrics, too [122]. It was proven that peroxyacids bonding to the fabrics was stable over extended periods of storage, whilst their antimicrobial activity appeared to be diminished after several washing and recharging cycles [118,121].

\section{Conclusions}

Antimicrobial functional finishing for textiles intended for biomedical applications is becoming pervasive. Most major fibers and fabrics producers have added antimicrobial products to their product lines. Significant differences still remain in terms of efficacy, kinetics, and durability between various products, but this field is active as more improvements are still necessary.

Biocides are a chemically diverse group of agents. Critical features that govern interactions between microbes and biocides are: the physico-chemical characteristics of the chemical agent, cell morphology, and the microorganism physiology. Antibacterial action includes membrane disruption, macromolecule disfunction, and metabolic inhibition. Disinfection kinetics offer a measure to differentiate between various biocides. The increasingly demand for antimicrobial textiles requires more sophisticated biocidal systems. Modern approaches focus on combinations of various agents able to act synergistically, intracellular biocide delivery through cellular transport processes able to overcome cellular barriers, targeted discharge of biocide.

This paper presented, in a concise manner, only some synthetic agents, their mode of action and some applications, being a part of an extensive study currently in progress. Further papers will review other biocides, such as metals, their oxides and salts (silver, copper, cobalt, etc), metal-organic complexes (e.g., zinc pyrithione), natural antimicrobials (chitosan), plant extracts (essential oils, dyes, germicides). Technological aspects will be also discussed, as well as particular aspects concerning methods of application and durability of these functional finishing treatments of textiles.

\section{References}

1. Windler, L.; Height, M.; Nowack, B. Comparative evaluation of antimicrobials for textile applications. Environment International, 2013, 53, pp. 62-73.

2. FAO, ICAC. A summary of the world apparel fiber consumption survey 2005-2008. Food and Agriculture Organization of the United Nation; International Cotton Advisory Committee; 2011. FAO and ICAC, 2011.

3. Ristić, T.; Zemljič, L. F.; Novak, M.; Kunčič, M. K.; Sonjak, S.; Cimerman, N. G.; Strnad, S. Antimicrobial efficiency of functionalized cellulose fibers as potential medical textiles. In Science against microbial pathogens: communicating current research and technological advances. Vol. 1 FORMATEX "Microbiology Series No. 3", Badajoz, Spain, 2011, pp. 36-51.

4. Ali, N. F.; El-Mohamedy, R. S. R.; Rajput, S. Improvement of antimicrobial activity for onion natural dyed fabrics through chitosan pretreatment. Journal of Applied Science Research, 2013, 9(8), pp. 4993-5002.

5. Gao, Y.; Cranston, R. Recent advances in antimicrobial treatments of textiles. Textile Research Journal, 2008, 78(1), pp. 60-72.

6. Hebeish, A. A.; Ali, N. F.; Abd El- Thalouth, J. I. Green strategy for development of antimicrobial printed textile fabrics. Research Journal of Textile \& Apparel, 2012, 16(1), pp. 77-85.

7. Pavlidou V., New Multifunctional Textiles: Antimicrobial Treatments. In "Proceedings of the Intelligent Textile Structures-Application, Production and Testing International Workshop", Thessaloniki, Greece 2005, http://centrum.tul.cz/centrum/itsapt/prezentace/wp2/113105EF.PPT (accessed May 14-th 2014). 
8. Antimicrobial Fabrics Help Fight War Against Germs, Press Release 2004-02-26, http://www.textilesintelligence. com/til/press.cfm?prid=325 (accessed May 14-th 2014).

9. Bshena, O.; Heunis T. D. J.; Dicks, L. M. T.; Klumperman, B. Antimicrobial fibers: therapeutic possibilities and recent advances. Future Medical Chemistry, 2011,3, pp. 1821-1847.

10. Dastjerdi, R.; Montazer, M. A review on the application of inorganic nano-structured materials in the modification of textiles: Focus on anti-microbial properties. Colloids and Surfaces B, 2010, 79, pp. 5-18.

11. Joshi, M.; Wazed, Ali, S.; Purwar, R. Ecofriendly antimicrobial finishing of textiles using bioactive agents based on natural products. Indian Journal of Fibre \& Textile Research, 2009, 34, pp. 295-304.

12. Sadaf, S.; Saeed, M.; Kalsoom, S. Comparison of treated and untreated cotton fabric with antimicrobial finish. Science International (Lahore), 2012, 24(3), pp. 293-297.

13. Williams, J. F.; Halo Source, V.; Cho, U. Antimicrobial functions for synthetic fibers: Recent developments. American Association of Textile Chemists and Colorists Review (AATCC Review), 2005, 5(4), pp. 17-21.

14. Ye, W.; Xin, J. H.; Li, P.; Lee, K.-L. D.; Kwong, T.-L. Durable antibacterial finish on cotton fabric by using chitosan-based polymeric core-shell particles. Journal Applied of Polymer Science, 2006, 102, pp. 1787-1793.

15. Ranganath, A. S. A comparative evaluation of antimicrobial properties and durability to laundering of selected antimicrobial agents on a hospital textile. Ph.D. Thesis, Colorado State University, Colorado, USA, 2011.

16. Simoncic, B.; Tomsic, B. Structures of novel antimicrobial agents for textiles - A review. Textile Research Journal, 2013, 80(16), pp. 1721-1737.

17. Schindler, W. D., Hauser, P. J. Chemical finishing of textiles. Woodhead Publishing Ltd, Cambridge, 2004, 216 p.

18. Dring, I. Anti-microbial, rotproofing and hygiene finishes. In "Textile Finishing", Heywood, D. (Ed.), Society of Dyers and Colourists, Bradford, 2003, pp. 351-371.

19. Mahltig, B.; Haufe, H.; Böttcher, H. Functionalization of textiles by inorganic sol-gel coatings. Journal Materials Chemistry, 2005, 15(41), pp. 4385-4398.

20. Vigo, T. L. Protection of Textiles from Biological Attack. In "Functional Finishes, Part A, Chemical Processing of Fibres and Fabrics, Handbook of Fiber Science and Technology, Vol. II”, Sello, S. B. (Ed.), Marcel Dekker: New York, 1983, pp. 367-426.

21. Glaser, A. The ubiquitous Triclosan - A common antibacterial agent exposed. Pesticides and You, 2004, 24(3), pp. 12-17.

22. Schindler, W. D.; Hauser, P. J. Chemical finishing of textiles. Woodhead Publishing Limited, Cambridge, 2004, $176 \mathrm{p}$.

23. Murguia, M. C.; Machuca, L. M.; Lura, M. C.; Cabrera M. I.; Grau, R. J. Synthesis and properties of novel antifungal gemini compounds derived from N-acetyl diethanolamines. Journal of Surfactants and Detergents, 2008, 11, pp. 223-230.

24. Laatiris, A.; El Achouri, M.; Infante, M. R.; Bensouda, Y. Antibacterial activity, structure and CMC relationships of alkanediyl $\alpha, \omega$-bis(dimethylammonium bromide) surfactants. Microbiological Research, 2008, 163 , pp. 645-650.

25. Massi, L.; Guittard, F.; Levy, R.; Gêribaldi, S. Enhanced activity of fluorinated quaternary ammonium surfactants against Pseudomonas aeruginosa. European Journal of Medicinal Chemistry, 2009, 44, pp. 16151622.

26. Ahlström, B.; Chelminska-Bertilsson, M.; Thompson, R. A.; Edebo, L. Long-chain alkanoylcholines, a new category of soft antimicrobial agents that are enzymatically degradable. Antimicrobial Agents and Chemotherapy, 1995, 39(1), pp. 50-55.

27. Tiller, J. C.; Liao, C. J.; Lewis, J.; Klibanov, A.M. Designing surfaces that kill bacteria on contact. Proceedings. Natl. Acad. Sci. U.S.A., 2001, vol. 98, pp. 5981-5985.

28. Ascenzi J. M. Handbook of disinfectants and antiseptics, Marcel Dekker: New York, 1996, 300 p.

29. Gilbert, P.; Moore, L. E. Cationic antiseptics: Diversity of action under a common epithet. Journal of Applied Microbiology, 2005, 99(4), pp. 703-715.

30. Marini, M.; Bondi, M.; Iseppi, R.; Toselli, M.; Pilati, F. Preparation and antibacterial activity of hybrid materials containing quaternary ammonium salts via sol-gel process. European Polymer Journal, 2007, 43(8), pp. 36213628.

31. Owusu-Adom K.; Guymon, C. A. Photopolymerization kinetics of poly(acrylate)-clay composites using polymerizable surfactants. Polymer, 49(11), 2008, pp. 2636-2643.

32. Caillier, L.; de Givenchy, E.T.; Levy, R.; Vandenberghe, Y.; Géribaldi, S.; Guittard, F. Synthesis and antimicrobial properties of polymerizable quaternary ammoniums. European Journal of Medicinal Chemistry, 2009, 44(8), pp. 3201-3208.

33. Shao, H.; Jiang, L.; Meng, W. D.; Qing, F. L. Synthesis and antimicrobial activity of a perfluoroalkyl-containing quaternary ammonium salt. Journal of Fluorine Chemistry, 2003, 124, pp. 89-91.

34. Novak, B. M. Hybrid nanocomposite materials - between inorganic glasses and organic polymers. Advanced Materials, 1993, 5(6), pp. 422-433. 
35. Judeinstein, P.; Sanchez, C. Hybrid organic-inorganic materials: A land of multydisciplinarity. Journal of Material Chemistry, 1996, 6(4), pp. 511-525.

36. Nalwa H. S. Handbook of Organic-Inorganic Hybrid Materials and Nanocomposites; American Scientific Publisher, Stevenson Ranch, 2003, 382 p.

37. Wang, X.; Wang, C. The antibacterial finish of cotton via sols containing quaternary ammonium salts. Journal of Sol-Gel Science and Technology, 2009, 50, pp. 15-21.

38. Isquith, A. J.; Abbott, E. A.; Walters, P. A. Surface-bonded antimicrobial activity of an organosilicon quaternary ammonium chloride. Applied Microbiology, 1972, 24, pp. 859-863.

39. Tomšič, B.; Simončič, B. Antimicrobial activity of 3-(trimethoxysilyl)propyldimethyl-alkilamonium chloride. Tekstilec, 2005, 48, pp. 79-87.

40. Li, Z.; Lee, D.; Sheng, X.; Cohen, R. E.; Rubner, M. F. Two-level antibacterial coating with both release-killing and contact killing capabilities. Langmuir, 2006, 22, pp. 9820-9823.

41. Yu, M.; Gu, G.; Meng, W. D.; Qing, F. L. Superhydrophobic cotton fabric coating based on a complex layer of silica nanoparticles and perfluorooctylated quaternary ammonium silane coupling agent. Applied Surface Science, 2007, 253, pp. 3669-3673.

42. Jausovec, D.; Angelescu, D.; Vončina, B.; Nylander, T.; Lindman, B. The antimicrobial reagent role on the degradation of model cellulose film. Journal of Colloid and Interface Science, 2008, 327, pp. 75-83.

43. Pant, R. R.; Buckley, J. L.; Fulmer, A. P.; Wynne, J. H.; McCluskey, M. D.; Phillips, J. P. Hybrid siloxane epoxy coatings containing quaternary ammonium moieties. Journal Applied Polymer Science, 2008, 110, pp. 3080-3086.

44. Chojnowski, J.; Fortuniak, W.; Rosciszewski, P.; Werel, W.; Lukasiac, J.; Kamysz, W.; Halasa, R. Polysilsesquioxanes and oligosilsesquioxanes substituted by alkylammonium salts as antibacterial biocides. Journal of Inorganic and Organometallic Polymers Materials, 2006, 16, pp. 219-230.

45. Majumdar, P.; Lee, E.; Gubbins, N.; Stafslien, S. J.; Daniels, J.; Thorson, C. J.; Chisholm, B. J. Synthesis and antimicrobial activity of quaternary ammonium-functionalized POSS (Q-POSS) and polysiloxane coatings containing Q-POSS. Polymer, 2009, 50, pp. 1124-1133.

46. Russell, A. D. Bacterial adaptation and desistance to antiseptics, disinfectants and preservatives is not a new phenomenon. Journal of Hospital Infection, 2004, 57, pp. 97-104.

47. A New, Durable Antimicrobial Finish for Textiles, http://microbeshield.com/techdocs/New_Durable Antimicrobial_Finish_for_Textiles_4A1-F.pdf (accessed June 2007).

48. Majumdar, P.; Lee, E.; Patel, N.; Stafslien, S. J.; Daniels, J.; Chisholm, B. J. Development of environmentally friendly, antifouling coatings based on tethered quaternary ammonium salts in a crosslinked polydimethylsiloxane matrix. Journal of Coatings and Technology Research, 2008, 5, pp. 405-417.

49. Mizerska, U.; Fortuniak, W.; Chojnowski, J.; Halasa, R.; Konopacka, A.; Werel, W. Polysiloxane cationic biocides with imidazolium salt (ImS) groups, synthesis and antibacterial properties. European Polymer Journal, 2009, 45, pp. 779-787.

50. Ma, M.; Sun, Y.; Sun, G. Antimicrobial cationic dyes. Part 1: Synthesis and characterization. Dyes and Pigments, 2003, 58, pp. 27-35.

51. Ma, M.; Sun, G. Antimicrobial cationic dyes. Part 3: Simultaneous dyeing and antimicrobial finishing of acrylic fabrics. Dyes and Pigments, 2005, 66, pp. 33-41.

52. Liu, S.; Ma, J.; Zhao, D. Synthesis and characterization of cationic monoazo dyes incorporating quaternary ammonium salts. Dyes and Pigments, 2007, 75, pp. 255-262.

53. Zhao, T.; Sun, G.; Song, X. An antimicrobial cationic reactive dye: synthesis and applications on cellulosic fibers. Journal Applied of Polymer Science, 2008, 108, pp. 1917-1923.

54. Liu, J.; Sun, G. The synthesis of novel cationic anthraquinone dyes with high potent antimicrobial activity. Dyes and Pigments, 2008, 77, pp. 380-386.

55. Liu, J.; Sun, G. The biocidal properties of anthraquininoid dyes. Dyes and Pigments, 2009, 81(3), pp. $231-234$.

56. Chen C. Z.; Beck-Tan, N. C.; Dhurjati, P.; van Dyk, T. K.; LaRossa, R. A.; Cooper S. L. Quaternary ammonium functionalized Poly(propylene imine) dendrimers as effective antimicrobials: structure activity. Biomacromolecules, 2000, 1(3), pp. 473480.

57. Hummelen J. C.; van Dongen, J. L. J.; Meijer, E. W. Electrospray mass spectroscopy of poly(propylene imine) dendrimers-The issue of dendrimeric purity or polydisperity. Chemistry - A European Journal, 1997, 3(9), pp. 1489-1493.

58. Weener J. W.; van Dongen, J. L. J.; Meijer, E. W. Enhanced contrast ratios and rapid switching in electrochromics based on poly(3,4-propylenedioxythiophene) derivatives. Journal of the American Chemical Society, 1999, 121(44), pp. 10346-10355.

59. Kim, Y. H.; Sun, G. Durable antimicrobial finishing of nylon fabrics with acid dyes and a quaternary ammonium salt. Textile Research Journal, 2001, 71, pp. 318-323.

60. Son, Y. A.; Sun, G. Durable antimicrobial nylon 66 fabrics: Ionic interactions with quaternary ammonium salts. Journal Applied of Polymer Science, 2003, 90, pp. 2194-2199. 
61. Kim, Y. H.; Sun, G. Functional finishing of acrylic and cationic dyeable fabrics: intermolecular interactions. Textile Research Journal, 2002, 72, pp. 1052-1056.

62. Cai, Z. S.; Sun, G. Antimicrobial finishing of acrilan fabrics with cetylpyridinium chloride. Journal Applied Polymer Science, 2004, 94, pp. 243-247.

63. Cai, Z. S.; Sun, G. Antimicrobial finishing of acrilan fabrics with cetylpyridinium chloride: Affected properties and structures. Journal Applied of Polymer Science, 2005, 97, 1227-1236.

64. Kim, Y. H.; Sun, G. Dye molecules as bridges for functional modifications of nylon: Antimicrobial functions. Textile Research Journal, 2000, 70, pp. 728-733.

65. Zhu, P.; Sun, G. Antimicrobial finishing of wool fabrics using quaternary ammonium salts. Journal Applied Polymer Science, 2004, 93, pp. 1037-1041.

66. Zhao, T.; Sun, G. Antimicrobial finishing of wool fabrics with quaternary aminopyridinium salts. Journal Applied Polymer Science, 2006, 103, pp. 482-486.

67. Diz, M.; Jocic, D.; Infante, M. R.; Erra, P. Reaction of a new thiol cationic surfactant with Bunte salt in wool fibers. Textile Research Journal, 1997, 67, pp. 486-493.

68. Diz, M.; Infante, M. R.; Erra, P.; Manresa, A. Antimicrobial activity of wool treated with a new thiol cationic surfactant. Textile Research Journal, 2001, 71, pp. 695-700.

69. Son, Y. A.; Kim, B. S.; Ravikumar, K.; Lee, S. G. Imparting durable antimicrobial properties to cotton fabrics using quaternary ammonium salts through 4-aminobenzenesulfonic acid -chloro-triazine adduct. European Polymer Journal, 2006, 42, pp. 3059-3067.

70. Isquith, A. J.; Abbott, E. A.; Walters, P. A. Surface bonded antimicrobial activity of organosilicon quaternary ammonium chloride. Applied Microbiology, 1973, 25(2), pp. 253-256.

71. Abbott, E. A.; Isquith, A. J. Method of inhibiting the growth of bacteria and fungi using organosilicon amines. USA Patent, 1975, No 3860709.

72. Abbott, E. A.; Isquith, A. J.; Walters, P. A. Algicidal Surfaces. USA Patent, 1975, No. 3865728.

73. Broughton, R. M. Jr.; Worley, S. D.; Cho, U.; Lin J.; Sun G. Incorporation of antimicrobial materials in fabric. Proceedings of INTC - International Nonwoven and Fibre Industries, 2001, Baltimore, MD.

74. Vetter, W.; Janussen, D. Halogenated natural products in five species of Antarctic sponges: compounds with POP-like properties? Environmental Science and Technology, 2005, 39(11), pp. 3889-3895.

75. Montaño, M.; Gutleb, A. C.; Murk, A. J. Persistent toxic burdens of halogenated phenolic compounds in humans and wildlife. Environmental Science and Technology, 2013, 47(12), pp. 6071-6081.

76. Orhan M.; Kut, D.; Gunesoglu, C. Use of triclosan as antibacterial agent in textiles. Indian Journal of Fibre and Textile Research, 2007, 32, pp.114-118.

77. Orhan, M., Kut, D.; Gunesoglu, C. Improving the antibacterial activity of cotton fabrics finished with triclosan by the use of 1,2,3,4-butanetetracarboxylic acid and citric acid. Journal of Applied Polymer Science, 2009, 111, pp. 1344-1352.

78. Guan, Y.; Qian, L.; Xiao, H. Novel antimicrobial host-guest complexes based on cationic $\beta$-cyclodextrin polymers and triclosan/butylparaben. Macromolecular Rapid Communications, 2007, 28, pp. 2244-2248.

79. Qian, L.; Guan, Y.; Ziaee, Z.; He, B.; Zheng, A.; Xiao, H. Rendering cellulose fibers antimicrobial using cationic $\beta$-cyclodextrin-based polymers included with antibiotics. Cellulose, 2009, 16, pp. 309-317.

80. Goetzendorf-Grabowska, B.; Krolikowska, H.; Gadzinowski, M. Polymer microspheres as carriers of antibacterial properties of textiles: A preliminary study. Fibres and Textiles in Eastern Europe, 2004, 12, pp. 6264.

81. Payne, S. A. Antimicrobial superfinish and method of making. USA Patent, 2004, No. 20040077747.

82. Mikolajczyk, T.; Wolowska-Czapnik D. Highly porous polyacrylonitrile fibres with antibacterial and antifungal properties. Fibres and Textiles in Eastern Europe, 2002, 10, pp. 18-22.

83. Kalyon, B. D.; Olgun, U. Antimicrobial efficacy of triclosan-incorporated polymers. American Journal of Infection Control, 2001, 29, pp. 123-125.

84. Iconomopoulou, S. M.; Andreopoulou, A. K.; Soto, A.; Kallitsis, J. K.; Voyiatzis, G. A. Incorporation of low molecular weight biocides into polystyrene-divinyl benzene beads with controlled release characteristics. Journal of Controlled Release, 2005, 102, pp. 223-233.

85. Mao, J. W.; Murphey, L. Durable freshness for textiles. 2001, American Association of Textile Chemists and Colorists Review (AATCC Review), 1, pp. 28-31.

86. Mansfield R. G. Keeping it fresh. Textile World, 2002, 152, pp. 42-45.

87. Windler, L.; Height, M.; Nowack, B. Review - Comparative evaluation of antimicrobials for textile applications. Environment International, 2013, 53, pp. 62-73.

88. Microban Products Company, http://www.microban.com (accesed May 14-th 2014).

89. Veldhoen, N.; Skirrow, R.; Osachoff, H.; Wigmore, H.; Clapson, D.; Gunderson, M.; van Aggelen, G.; Helbing, C. The bactericidal agent triclosan modulates thyroid hormone-associated gene expression and disrupts postembryonic anuran development. Aquatic Toxicology, 2006, 80, pp. 217-227. 
90. Foran, C. M.; Bennett, E. R.; Benson, W. H. Developmental evaluation of a potential non-steroidal estrogen: triclosan. Marine Environmental Research, 2000, 50, pp. 153-156.

91. Bhargava, H. L. P. Triclosan: Applications and safety. American Journal of Infection Control, 1996, 24, pp. 209-218.

92. Calafat, A. M.; Ye, X.; Wong, L.-Y.; Reidy, J. A.; Needham, L. L. Urinary concentrations of triclosan in the U.S. population: 2003-2004. Environmental Health Perspectives, 2008, 116(3), pp. 303-307.

93. Krebs, F. C.; Miller, S. R.; Ferguson, M. L.; Labib, M.; Rando, R. F.; Wigdahl, B. Polybiguanides, particularly polyethylene hexamethylene biguanide, have activity against human immunodeficiency virus type 1 . Biomedicine and Pharmacotherapy, 2005, 59, pp. 438-445.

94. Kawabata, A.; Taylor, J. A. The effect of reactive dyes upon the uptake and antibacterial efficacy of poly(hexamethylenebiguanide) on cotton. Part 3: Reduction in the antibacterial efficacy of poly(hexamethylene biguanide) on cotton dyed with bis(monochlorotriazinyl) reactive dyes. Carbohydrate Polymers, 2007, 67, pp. 375-389.

95. Mulder, G. D.; Cavorsi, J. P.; Lee, D. K. Polyhexamethylenebiguanide (PHMB): An addendum to current topical antimicrobials. Wounds, 2007, 19, pp. 173-182.

96. Moore, K.; Gray, D. Using PHMB antimicrobial to prevent wound infection. Wounds UK, 2007, 3, pp. 96-102.

97. de Paula, G. F.; Netto, G. I.; Mattoso, L. H. C. Physical and chemical characterization of poly(hexamethylene biguanide) hydrochloride. Polymers, 2011, 3, pp. 928-941.

98. Koburger, T.; Hübner, N.-O.; Braun, M.; Siebert, J.; Kramer, A. Standardized comparison of antiseptic efficacy of triclosan, PVP-iodine, octenidine dihydrochloride, polyhexanide and chlorhexidine digluconate. Journal of Antimicrobial Chemotherapy, 2010, 65, pp. 1712-1719.

99. Kaehn, K. Polihexanide: A safe and highly effective biocide. Skin Pharmacology and Physiology, 2010, 23(suppl. 1), pp. 7-16.

100. Blackburn, R. S.; Harvey, A. L.; Kettle, L.; Manian, A. P.; Payne, J. D.; Russell, S. J. Sorption of chlorhexidine on cellulose: mechanism of binding and molecular recognition. Journal of Physical Chemistry, Part B, 2007, 111, pp. 8775-8784.

101. http://www.archbiocides.com/Products/Brand/vantocil.htm (accesed May 14-th 2014).

102. http://www.archbiocides.com/Splash/purista.htm (accesed May 14-th 2014).

103. Qian, L.; Sun, G. Durable and regenerable antimicrobial textiles: chlorine transfer among halamine structures. Industrial and Engineering Chemical Research, 2005, 44, pp. 852-856.

104. Barnes, K.; Liang, J.; Wu, R.; Worley, S. D.; Lee, J.; Broughton, R. M.; Huang, T. S. Synthesis and antimicrobial applications of 5,50-ethylenebis[5-methyl-3-(3-triethoxysilylpropyl)hydantoin]. Biomaterials, 2006, 27, pp. 4825-4830.

105. Lin, J.; Cammarata, V.; Worley, S. D. Infrared characterization of biocidal nylon. Polymer, 2001, 42, pp. 7903-7906.

106. Ren, X.; Kocer, H. B.; Kou, L.; Worley, S. D.; Broughton, R.M.; Tzou, Y. M.; Huang, T. S. Antimicrobial polyester. Journal of Applied Polymer Science, 2008, 109, pp. 2756-2761.

107. Ren, X.; Kocer, H. B.; Worley, S. D.; Broughton, R. M.; Huang, T. S. Rechargeable biocidal cellulose: synthesis and application of 3-(2,3-dihydroxypropyl)-5,5-dimethylimidazo-lidine-2,4-dione. Carbohydrate Polymers, 2009, 75, pp. 683-687.

108. Liang, J.; Chen, Y.; Barnes, K.; Wu, R.; Worley, S. D.; Huang, T. S. N. N-halamine/quat siloxane copolymers for use in biocidal coatings. Biomaterials, 2006, 27, pp. 2495-2501.

109. Lin, J.; Winkelman, C.; Worley, S. D.; Broughton, R. M.; Williams, J. F. Antimicrobial treatment of nylon. Journal of Applied Polymer Science, 2001, 81, pp. 943-947.

110. Lin, J.; Winkelmann, C.; Worley, S. D.; Kim, J. H.; Wei, C. I.; Cho, U. C.; Broughton, R. M.; Santiago, J. I.; Williams, J. F. Biocidal polyester. Journal of Applied Polymer Science, 2002, 85, pp. 177-182.

111. Wu, F. C. Regenerable antimicrobial animal fiber materials. USA Patent, 2002, No. 20020123281(2002).

112. Sun, Y. Y.; Sun, G. Novel regenerable N-halamine polymeric biocides. III. Grafting hydantoin-containing monomers onto synthetic fabrics. Journal of Applied Polymer Science, 2001, 81, pp. 1517-1525.

113. Sun, Y. Y.; Sun, G. Novel refreshable N-halamine polymeric biocides: Grafting hydantoin-containing monomers onto high performance fibers by a continuous process. Journal of Applied Polymer Science, 2003, 88, pp. 1032-1039.

114. Obendorf, S. K.; Sun, G. Development of antimicrobial membrane for protective clothing. NTC Project: C05CR01. National Textile Center Research Briefs: June 2008. (http://www.ntcresearch. org/projectapp/?project=C05-CR01) (accesed May 14-th 2014).

115. Lee, J.; Broughton, R. M.; Worley, S. D.; Huang, T. S. Antimicrobial polymeric materials; cellulose and maramid composite fibers. Journal of Engineered Fibers and Fabrics, 2007, 2(4), pp. 25-32.

116. Li, S. Method of retaining antimicrobial properties on a halamine-treated textile substrate while simultaneously reducing deleterious odor and skin irritation effects. USA Patent, 2003, No. 6576154. 
117. Huang, L. K.; Sun, G. Durable and rechargeable antimicrobial cellulose with peroxy moieties. In the Book of Abstract of the Conference of the Fiber Society, 2004 Fall, Cornell University, Ithaca, NY, USA (www.thefibersociety.org/httpdocs/Assets/Past_Meetings/BooksOfAbstracts/2004_Fall_abstracts.pdf) (accesed May 14-th 2014).

118. Dettenkofer, M.; Block, C. Hospital disinfection: efficacy and safety issues. Current Opinion in Infectious Diseases, 2005, 18, pp. 320-325.

119. Huang, L. K.; Sun, G. Durable and regenerable antimicrobial cellulose with oxygen bleach: concept proofing. American Association of Textile Chemists and Colorists Review (AATCC Review), 2003, 3, pp. 17-21.

120. Ramachandran, T.; Rajendrakumar, K.; Rajendran, R. Antimicrobial textiles. An overview. IE(I) Journal-TX, 2004, 84, pp. 42-47.

121. Huang, L. K.; Sun, G. Durable and oxygen bleach rechargeable antimicrobial cellulose: sodium perborate as an activating and recharging agent. Industrial and Engineering Chemical Research, 2003, 42, pp. 5417-5422.

122. Sun, G.; Huang, L. K. Regenerable antimicrobial polymers and fibers with oxygen bleaches. USA Patent, 2005, No. 6962608. 